\title{
Hamster Female Protein, a Sex-limited Pentraxin, Is a Constituent of Syrian Hamster Amyloid
}

John E. Coe and Mary Jane Ross

U. S. Department of Health and Human Services, Public Health Service, National Institutes of Health, National Institute of Allergy and Infectious Diseases, Laboratory of Persistent Viral Diseases, Rocky Mountain Laboratories, Hamilton, Montana 59840

\begin{abstract}
Female protein (FP) is a pentraxin of Syrian hamster which is a homologue of two human pentraxins, C-reaction protein (CRP) and amyloid $P$ component (AP). Functionally, FP has been shown to be similar to CRP, although FP has more homology at the amino terminus with AP. The present work investigated amyloid in the Syrian hamster to determine whether FP was involved in a manner analogous to AP. FP was found to be a constituent of Syrian hamster amyloid. This conclusion was based on the following results: (a) FP was consistently detected in amyloid deposits by fluorescent microscopy with specific antisera; (b) The amount of FP extractable from hamster livers directly correlated with the presence of amyloid; and $(c){ }^{125} \mathrm{I}-\mathrm{FP}$ injected intravenously into amyloidotic hamsters rapidly left the intravascular compartment and was found subsequently in amyloid deposits. This unusual alteration of plasma metabolism and amyloid localization of ${ }^{125}$ I-FP was a characteristic finding in amyloidotic hamsters and was specific for ${ }^{125} \mathrm{I}$-FP. Therefore, as an amyloid component, FP appears to be functionally similar to human AP. However, FP synthesis is under sex steroid control and the unique sex-limited expression of this pentraxin was associated with an equally novel propensity for deposition of amyloid in female hamsters under normal or experimental conditions. Thus, a high serum level of FP, as found in normal females or diethylstilbestrol-treated males, was associated with enhanced amyloidosis. Although speculative at present, a primary role for serum FP in hamster amyloid deposition may be experimentally approachable by hormonal manipulation of FP synthesis.
\end{abstract}

\section{Introduction}

Amyloid was first recognized as an abnormal constituent of human tissues by Rokitansky in 1842 (1) and Virchow in 1858 (2). Since then amyloid has been found in most animals and the basic structure of these pathologic deposits appears to be similar (3). The major constituent is in a fibrillar form with a characteristic $\beta$-pleated sheet which can be derived from a number of proteins (AA protein, $L$ chain, prealbumin, etc.). Another protein called amyloid $\mathrm{P}$ (AP) ${ }^{1}$ component also is present. A primary or framework role for AP in fibril deposits has been speculated because AP is a constant constituent in

Address reprint requests to Dr. Coe.

Received for publication 11 February 1985

1. Abbreviations used in this paper: AP, amyloid P component; CRP, C-reactive protein; DES, diethylstilbestrol; FP, female protein; RGG, rabbit gamma globulin; SAP, serum amyloid $\mathrm{P}$ component.

The Journal of Clinical Investigation, Inc.

Volume 76 , July $1985,66-74$ amyloid with various fibrillar proteins and AP will form ordered structures by itself $(4,5)$. AP exists as a normal human serum constituent (called serum AP or SAP) and has been shown to be structurally similar (50-70\% homology) to human C-reactive protein (CRP) $(6,7)$. Homologues of human SAP and CRP have been found in a variety of animals $(8,9)$ and belong to a family of proteins called pentraxins (6). Pentraxins from horseshoe crab $(10)$, telost fish $(9,11)$, and humans are remarkably similar in structure and this conservative evolution implies an important but as yet unproven function for these proteins.

The Syrian hamster has an unusual sex-limited serum pentraxin called female protein (FP) $(12,13)$. So far, only in the Syrian hamster has a pentraxin gene come under such stringent sex hormone control (14). This has resulted in an unprecedented high concentration of this pentraxin in serum of female hamsters (1-2 mg/ml), whereas normal males have levels $\sim 100$-fold less as a result of testosterone suppression. Pentraxins of man and other mammals are known to increase serum levels during an acute phase response; however, a unique divergent response occurs in the hamster in which serum FP increases in male and decreases in female (15). Although the amino acid sequence at the $\mathrm{NH}_{2}$ terminus of FP is more similar to human SAP (identity at 19 of 23 residues) than to human CRP (13), hamster FP does exhibit a $\mathrm{Ca}^{++}$. dependent phosphorylcholine (PC)-binding capacity and does activate complement at the level of $\mathrm{Cl}$ (Etlinger, $\mathrm{H}$. M., and J. E. Coe, submitted for publication). These two important attributes (PC binding and complement activation) have been, up to now, associated only with CRP and its homologues rather than SAP-related proteins. On the other hand, a characteristic function of SAP (and SAP homologues) has been its consistent involvement in amyloid $(16,17)$. Accordingly, in the present study, the interaction of FP and hamster amyloid was examined to determine if FP was fulfilling a SAP-like role in hamsters. The results indicate that FP is a constituent of hamster amyloid, the deposition of which is directly associated with high serum levels of FP. Furthermore, in the amyloidotic hamster, the metabolism of injected FP is altered in that serum ${ }^{125} \mathrm{I}-\mathrm{FP}$ readily enters into and persists within the amyloid deposits in a specific fashion.

\section{Methods}

Animals. Randomly bred Syrian hamsters (Mesocricetus auratus) were obtained from the Rocky Mountain Laboratories hamster colony and maintained as before (15).

Histologic procedures. Tissue from necropsy was promptly frozen in liquid nitrogen and cut sections were reacted with a fluorescein isothiocyanate-conjugated (18) antibody specific for FP (13) and examined for fluorescent antibody by a Leitz Orthoplan microscope (E. Leitz, Inc., Rockleigh, NJ). Appropriate controls were included. Histologic sections (after paraffin embedding or quick-frozen) were stained 
by the alkaline Congo red method (19) and examined for typical birefringence by polarization microscopy. For autoradiography, slides containing the tissue sections were coated with NTB-2 emulsion (Eastman Kodak Co., Rochester, NY) and, after appropriate incubation, were developed and then stained with Congo red.

Amyloid experiments. Normal and experimental hamsters were tested for presence of amyloid by examination of histologic sections for Congo red birefringence. In preliminary studies, a variety of tissues was examined for amyloid; however, the liver, spleen and kidney were predominantly involved so that only these organs routinely were examined. The distribution of amyloid within various hamster tissues was found to be similar to previous reports (20): that is, amyloid deposits were characteristically found around central vein and portal areas of liver, in red pulp of spleen and, in the peritubular-glomerular location in kidney. In general, minimal amyloid involvement was detected first in the liver, then in spleen, and last in kidney. The amount of amyloid in the particular hamster was grossly quantified during histologic examination of the organs and varied from minimal (scarce occasional deposits in liver) to maximal (extensive liver, splenic white pulp, and kidney deposits). For experimental induction of amyloid, treatments were initiated in 3-mo-old hamsters, so incidence of experimental amyloid could be related to background amyloid from normal aging. Treatments consisted of $(a)$ a single diethylstilbestrol (DES) 12-mg pellet (Pfizer Inc., New York) surgically implanted subcutaneously every 3-4 mo and $(b) 1 \mathrm{ml}$ of $\mathrm{Na}$ caseinate (Difco Laboratories, Detroit, MI, $12.5 \%$ sterile) injected subcutaneously three times per week. Amyloid was also observed after injection of turpentine (15). Livers of pentobarbital anesthetized hamsters were perfused in situ with saline $(50 \mathrm{ml})$ by passing a cannula into the inferior vena cava and cutting the portal veins. FP was extracted from amyloid organs according to the procedure used for AP isolation (21). That is, hamster livers containing histologically detectable amyloid were individually weighed, homogenized (Sorvall Omni-mixer, DuPont-Sorvall, Newtown, CT), and repeatedly extracted (until OD $<0.1$ at $280 \mathrm{~nm}$, usually six extractions) with $80-\mathrm{ml}$ aliquots of $0.05 \mathrm{M} \mathrm{Na}$ citrate and/ or $0.15 \mathrm{NaCl}$. Tissue suspensions were centrifuged at $13,000 \mathrm{rpm}$ in a Sorvall RC5B, $4^{\circ} \mathrm{C}, 30$ min (DuPont-Sorvall). The supernatant fluids were pooled, concentrated by negative pressure dialysis, and quantified for FP by either ring diffusion or rocket electrophoresis using specific rabbit anti-FP in agarose (12).

Metabolic studies. Isolated FP and DEAE-purified rabbit gamma globulin (RGG) were iodinated with ${ }^{125}$ I (New England Nuclear, Boston, MA) as previously described (15). The individual hamster under pentobarbital anesthesia was injected intravenously with $\sim 10$ $\mu \mathrm{Ci}{ }^{125} \mathrm{I}$ in a $0.25-\mathrm{ml}$ volume (representing $\sim 15-30 \mu \mathrm{g}$ of protein). Retroorbital plasma samples $(0.05 \mathrm{ml})$ were obtained 1 min after injection (time 0 ) and at various intervals thereafter and counts per minute were determined in a gamma counter. Metabolic parameters were determined as before (15) according to Waldmann and Strober (22). Localization of ${ }^{125} \mathrm{I}$-protein in tissue was ascertained at various intervals after i.v. injection by the following procedure: Organs obtained at necropsy were weighed and counts per minute per gram of tissue was determined. To diminish plasma counts per minute content in liver counts per minute, the livers were perfused before removal. For all tissues, an individual animal's organ/plasma ratio (counts per minute per gram of tissue/counts per minute per $0.1 \mathrm{ml}$ of respective plasma) was calculated to normalize for potential plasma counts per minute. Therefore, a value of 1 would represent counts per minute of a tissue which could be explained by a $10 \%$ (weight) contamination of plasma.

\section{Results}

Incidence of amyloid in normal Syrian hamsters. Normal female hamsters developed amyloid at an earlier age than males (Table I); some amyloid (frequently minimal) was present in most females $(9$ of 10$)$ at 1 yr of age and moderate to maximal deposits were consistently found at $18 \mathrm{mo}$. In normal males, amyloid was not detected up to 1 yr of age and was seen in only 7 of 13 males at 24 mo and these deposits were usually quite minimal. The amount of amyloid was progressive with age especially in females and the extensive involvement seen in 18-mo-old females was not found in normal males, even after 3-4 yr of life (not shown). In our hamster colony, normal female hamsters rarely lived longer than 24-30 mo, whereas males older than $3 \mathrm{yr}$ were not uncommon.

Experimental induction of amyloid. Results of compiled experiments (Table I) indicated that amyloid was induced more easily in females than male hamsters. This was especially obvious when using $\mathrm{Na}$ caseinate, which after 5 mo of treatment produced amyloid in 12 of 15 females and only 1 of 14 males. Even after 7 or 9 mo of treatment, only minimal amyloid was detectable in males, whereas extensive deposits (and death) were characteristic in females. DES was more effective than

Table I. Incidence of Amyloid (Liver, Spleen, Kidney) in Normal/Experimental Syrian Hamsters After Various Intervals of Aging/Treatment

\begin{tabular}{|c|c|c|c|c|c|c|c|c|}
\hline $\begin{array}{l}\text { Age }(\mathrm{mo}) \\
\text { Duration of treatment, } \\
\text { experimental }(\mathrm{mo})\end{array}$ & 4 & 6 & 5 & 10 & 12 & 18 & 21 & 24 \\
\hline & $n$ & $n$ & $n$ & $n$ & $n$ & $n$ & $n$ & $n$ \\
\hline \multicolumn{9}{|l|}{ Normal } \\
\hline $\mathbf{F}$ & $0 / 8 \S$ & $0 / 4$ & $3 / 16$ & $0 / 4$ & $9 / 10$ & $10 / 10$ & $13 / 13$ & $4 / 4$ \\
\hline $\mathbf{M}$ & $0 / 8$ & $0 / 2$ & $0 / 6$ & $0 / 8$ & $0 / 12$ & $2 / 8$ & $3 / 10$ & $7 / 13$ \\
\hline \multicolumn{9}{|l|}{$\mathrm{Na} \mathrm{Cas}{ }^{*}$} \\
\hline $\mathbf{F}$ & & $3 / 5$ & $12 / 15$ & $6 / 6$ & $2 / 2$ & & & \\
\hline $\mathbf{M}$ & & $0 / 5$ & $1 / 14$ & $5 / 8$ & $8 / 16$ & & & \\
\hline \multicolumn{9}{|l|}{ DES $\ddagger$} \\
\hline $\mathbf{F}$ & $0 / 4$ & $9 / 11$ & $21 / 21$ & $5 / 5$ & Dead & & & \\
\hline $\mathbf{M}$ & $0 / 4$ & $6 / 11$ & $15 / 21$ & $2 / 3$ & $8 / 9$ & & & \\
\hline
\end{tabular}

* Na caseinate $12.5 \%$, sterile, $1 \mathrm{ml}$ injected subcutaneously three times per week starting at 3 mo of age. $¥ D E S 12$-mg pellet implanted subcutaneously at 3 mo of age. $\S$ Number of animals with amyloid/number animals examined. 
$\mathrm{Na}$ caseinate particularly in producing male amyloid (Table I). Differences in histologic appearance of amyloid or its organ distribution were not apparent when comparing DES- and $\mathrm{Na}$ caseinate-induced amyloid or when comparing males and females. However, the amount of amyloid in the organ was almost always greater in females than males regardless of induction scheme, and treated females would frequently die by $1 \mathrm{yr}$ of age with extensive amyloidosis.

Presence of FP in amyloid. Paired tissue sections were examined for presence of amyloid by Congo red birefringence and for FP by specific FA. A direct association between amyloid and detectable FP was found; that is, FP deposits in liver, spleen, and kidney were consistently detected only in areas of amyloid deposition and not in normal tissue. Fig. 1, $A$ and $B$, shows the typical discrete periportal localization of amyloid in liver as seen by transmitted $(A)$ and polarized $(B)$ light. Fig. 1, $C$ and $D$, shows similar areas of liver amyloid which were bright green by fluorescent microscopy after reaction with FITC-labeled anti-FP.

Extraction of FP from amyloidotic tissues. Originally amyloid $\mathrm{P}$ component was defined and isolated as a constituent of human amyloid (16). Accordingly, hamster amyloid tissues were treated in a fashion known to release AP from amyloid to determine the amount of extractable FP and to compare it
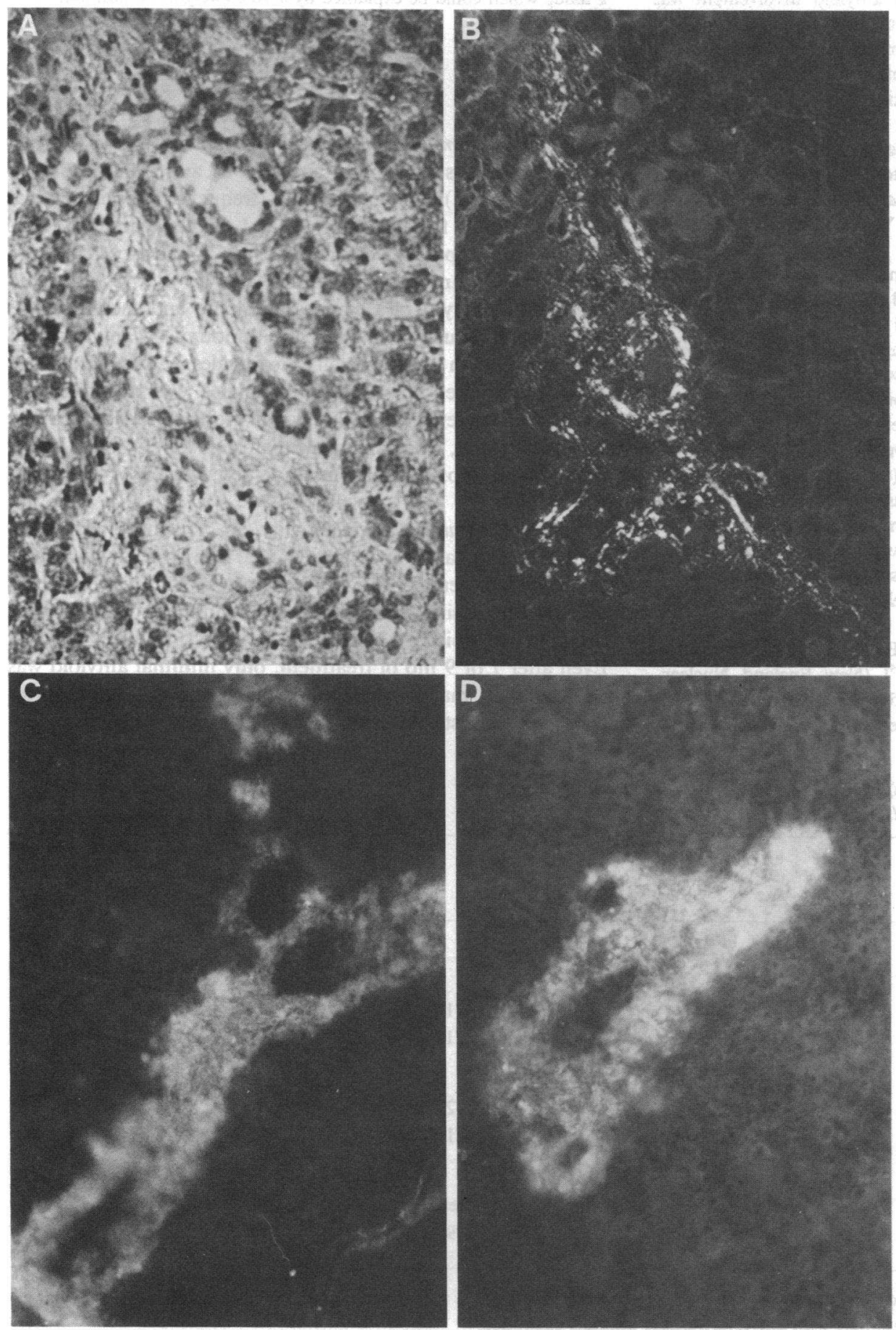

Figure 1. Paired photomicrographs of an amyloid hamster liver section (formalin fixed-paraffin embedded) stained with Congo red as seen by transmitted $(A)$ or polarized $(B)$ light. White areas in $B$ correspond to positive birefringence of amyloid accumulations in periportal area. $\times 200$. $(C, D)$ Photomicrograph of amyloid hamster liver (frozen section) stained with fluorescein isothiocyanate-labeled rabbit anti-FP. The white areas, which were bright green by fluorescence, coincided with the area of amyloid deposit seen in corresponding sections stained with Congo red and examined by polarized light microscopy. $C, \times 150 ; D, \times 250$. 
with serum FP (Table II). Normal livers of females contain significant amounts of FP because of ongoing hepatic synthesis (unpublished observations) and high serum levels. In situ perfusion, to remove serum FP, decreased the extractable FP content of normal female liver about twofold to $0.04 \mathrm{mg} / \mathrm{g}$ of liver. Among females, more FP was extracted from amyloidotic livers than from normal livers, and livers with more amyloid by histologic examination (such as the DES-induced group) yielded more FP than less affected livers ( $\mathrm{Na}$ caseinate or old age groups). The serum levels of FP were not too disparate in these experimental and normal female hamsters, although decreased serum levels have been noted in older females (12).

Normal male liver did not yield measurable amounts of extractable FP (Table II), consistent with data from metabolic and hepatic cell culture studies which indicate a very low synthesis rate in normal males (15 and unpublished data). However, treatments that result in amyloidosis also result in increased serum levels. Therefore, for control purposes, liver FP content was determined in three male hamsters 1 mo after DES, when serum FP was increased (12), but before amyloid development (Table I). The extractable FP $(0.031 \mathrm{mg} / \mathrm{g})$ in this "early DES" group was similar to that of normal female liver $(0.04 \mathrm{mg} / \mathrm{g})$. However, more FP $(0.1 \mathrm{mg} / \mathrm{g})$ was found in amyloid livers after longer DES treatment even though serum FP did not increase further (12).

Small amounts of amyloid were found in some normal old male hamsters (Table I), and detectable amounts of FP were extractable from these livers only when amyloid was present (Table II). In preliminary studies, FP isolated from amyloid appears identical to serum FP.

Serum metabolism of FP in normal and hormonally manipulated hamsters. The plasma disappearance of ${ }^{125} \mathrm{I}-\mathrm{FP}$ was different in males when compared to females (Fig. 2); that is, ${ }^{125}$ I-FP characteristically disappeared more rapidly from the serum of normal males during the initial phase of extravascular equilibration, although the terminal linear slope was similar in both sexes (called a "male type" of distribution). This rapid

Table II. Female Protein Content of Normal and Amyloid Livers, Individually Homogenized and Extracted by Citrate/Saline Washes (mg FP/g Liver)

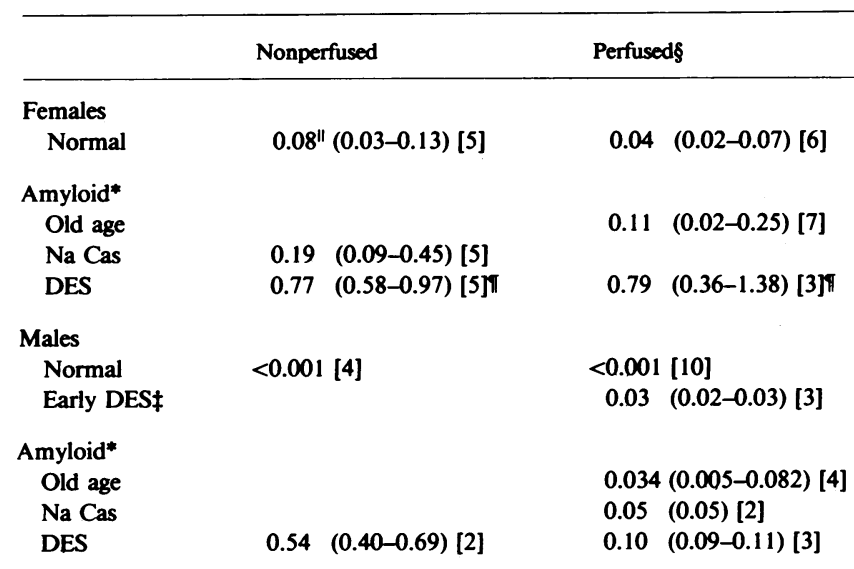

* Normal and experimental amyloid as in Table I.

₹ Livers harvested $1 \mathrm{mo}$ after implantation of $12 \mathrm{mg}$ of DES (preamyloid).

$\S$ Perfused with $50 \mathrm{ml}$ of phosphate-buffered saline.

"Arithmetic mean (range) [number of animals].

I Serum FP levels in normal range $(0.72-1.13 \mathrm{mg} / \mathrm{ml})$.

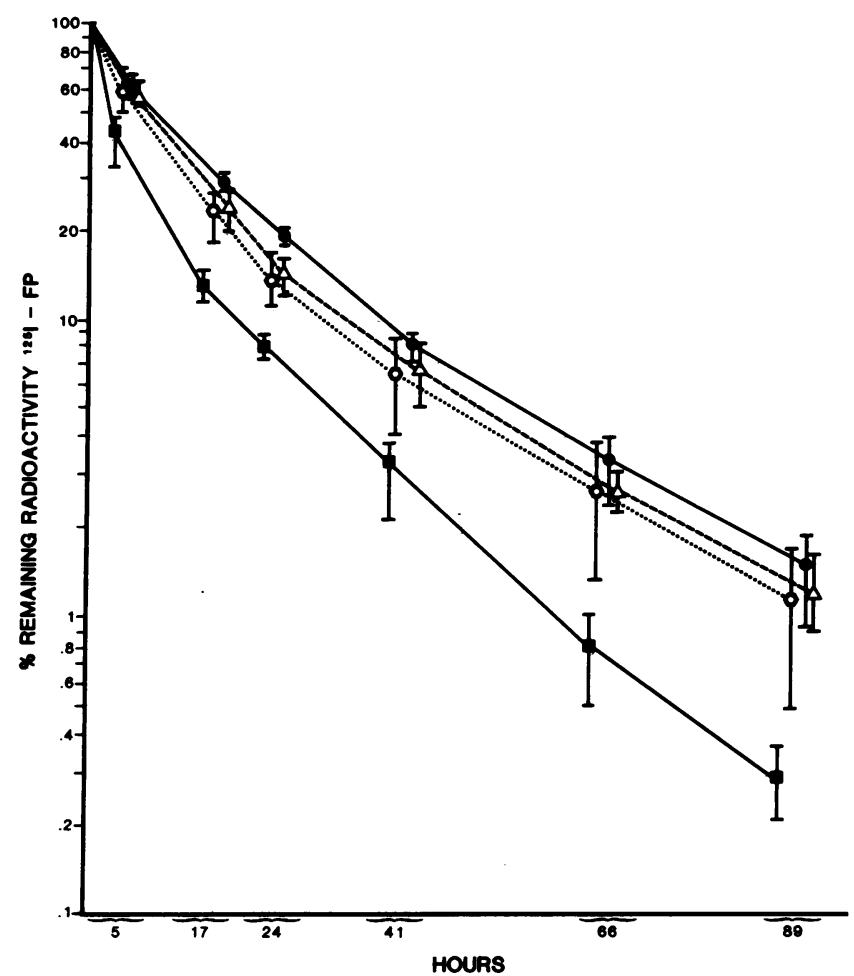

Figure 2. ${ }^{125}$ I-FP disappearance from plasma of normal hamsters and hamsters after 3 wk of DES treatment, before amyloid appearance. The mean and range (brackets) for groups of four animals each were plotted from injection at time 0 . Normal males ( $(\square)$ typically have a greater extravascular distribution than normal females (๑). However, a "female type" plasma metabolism curve was found in early DES males $(\times 3)(\Delta)$ when serum FP levels had increased from 0.01 to 0.5 $\mathrm{mg} / \mathrm{ml}$. ${ }^{125} \mathrm{I}-\mathrm{FP}$ metabolism curve was not changed in early DES females $(\times 4)(0)$.

extravascular transfer presumably was related to the low serum level of FP, as a "female type" of distribution was found in males 3 wk after injection with DES (early DES males, Fig. 2). At this time, FP serum levels in the males had increased $\sim 50$-fold $(0.5 \mathrm{mg} / \mathrm{ml})$ and amyloid was not present. Similarly, in other studies, the ${ }^{125} \mathrm{I}-\mathrm{FP}$ metabolism was changed to that characteristic of the other sex when FP levels were increased in males by castration or decreased in females by testosterone injection. In females, metabolism of intravenously injected ${ }^{125} \mathrm{I}-\mathrm{FP}$ was not altered when early DES-treated females (preamyloid) were tested (Fig. 2).

Serum metabolism of ${ }^{125}$ I-FP in amyloidotic hamsters. The plasma disappearance of ${ }^{125} \mathrm{I}-\mathrm{FP}$ was evaluated in amyloidotic hamsters to determine whether the FP metabolism was changed in the presence of the extravascular pool of amyloid FP. The plasma metabolism of ${ }^{125} \mathrm{I}$-FP was significantly altered by amyloidosis as seen in Fig. 3, an experiment with 10 amyloidotic males and females (from DES treatment and old age, respectively). When compared to normal females (or males with increased serum FP), ${ }^{125} \mathrm{I}$-FP rapidly disappeared from the intravascular compartment of amyloidotic hamsters and subsequently was metabolized at a slower rate $\left(t_{1 / 2}\right.$ from terminal slope $b[23] \sim 30 \mathrm{~h}$ ). This typical "amyloid pattern" of ${ }^{125} \mathrm{I}$ FP plasma disappearance has been seen with seven other ${ }^{125} \mathrm{I}$ FP preparations injected into 32 other amyloidotic Syrian hamsters ( 21 females and 11 males with amyloid after treatment 


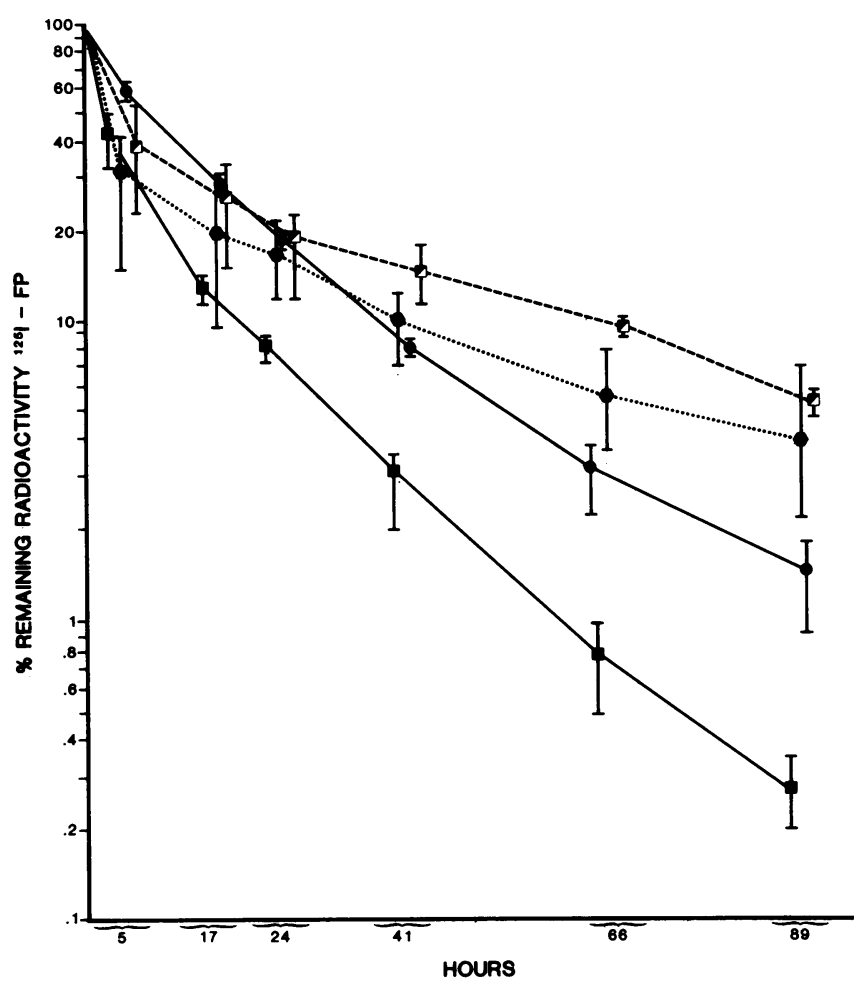

Figure 3. ${ }^{125}$ I-FP plasma disappearance in amyloidotic hamsters (a group of four old females [च] and a group of six DES-treated males

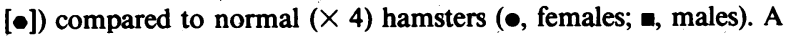
rapid intravascular loss with prolonged linear slope was characteristic for both male and female hamsters with amyloid in liver, spleen, and kidney.

with DES and/or $\mathrm{Na}$ caseinate). In all of these amyloidotic hamsters, the amyloid pattern of ${ }^{125} \mathrm{I}-\mathrm{FP}$ plasma metabolism was consistently seen and only seen when moderate amyloid deposits were detectable in liver, spleen, or kidney.

Another example of female propensity for amyloid formation was seen after turpentine injection. Fig. 4 compares the plasma disappearance of ${ }^{125} \mathrm{I}$-FP in three female hamsters with liver amyloid induced by turpentine injection 5 mo before. In contrast, three male hamsters injected with turpentine at the same time did not develop amyloid, and plasma disappearance of ${ }^{125} \mathrm{I}-\mathrm{FP}$ was similar to normal male controls. Thus, amyloid induced by turpentine injection also results in the characteristic alteration of ${ }^{125} \mathrm{I}$-FP plasma metabolism.

Serum metabolism of other proteins in amyloidotic hamsters. The question arises whether this effect of amyloid was specific for ${ }^{125} \mathrm{I}$-FP or also seen when other ${ }^{125} \mathrm{I}$ proteins were injected. The plasma disappearance of ${ }^{125}$ I RGG was found to be similar in male and female hamsters without or with amyloid (Fig. 5). Similar results were obtained with ${ }^{125}$ I-bovine serum albumin and ${ }^{125} I$ hamster serum albumin (not shown). With all three of these proteins, the terminal (e.g., after $40 \mathrm{~h}$ ) plasma levels of ${ }^{125} \mathrm{I}$ were generally less in amyloid animals than in controls, perhaps reflecting some loss via amyloidotic kidneys. In no instance with these ${ }^{125} \mathrm{I}$-proteins was a slower protein metabolism (terminal linear slope) detected in amyloid animals. In contrast, the slower terminal plasma disappearance of ${ }^{125}$ I-FP was a characteristic finding in amyloidotic hamsters.

Organ distribution of ${ }^{125} I-F P$ and ${ }^{125} I-R G G$ in normal and

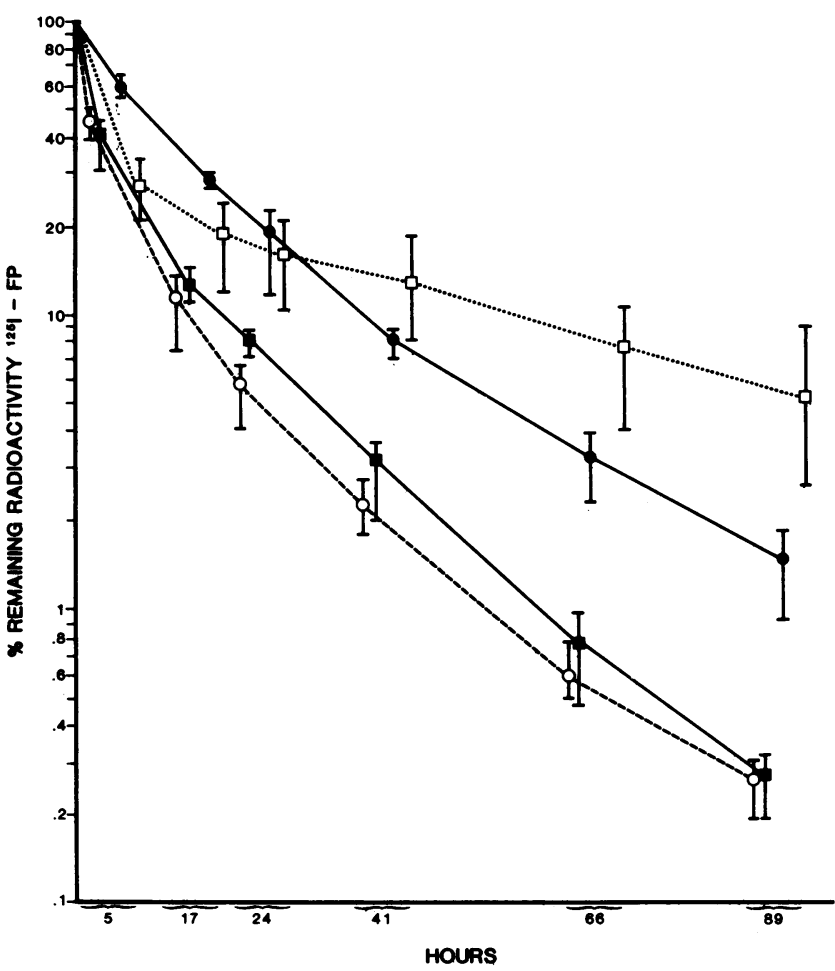

Figure 4. ${ }^{125}$ I-FP plasma disappearance in Syrian hamsters previously injected with turpentine, a treatment associated with amyloid formation in females but not in males. (๑) Normal females $(\times 4)$; (a) normal males $(\times 4)$. Presence of amyloid in turpentine females $(\square)$ $(\times 3)$ was correlated with "amyloid pattern" of ${ }^{125}$ I-FP metabolism whereas normal ${ }^{125} \mathrm{I}-\mathrm{FP}$ metabolism was found in turpentine nonamyloidotic males $(0)(\times 3)$.

amyloid hamsters. The hamsters injected with ${ }^{125} \mathrm{I}-\mathrm{FP}$ on day 0 in Fig. 3 were necropsied (after liver perfusion) on day 7 . The amount of ${ }^{125}$ I-FP was determined per gram of liver,

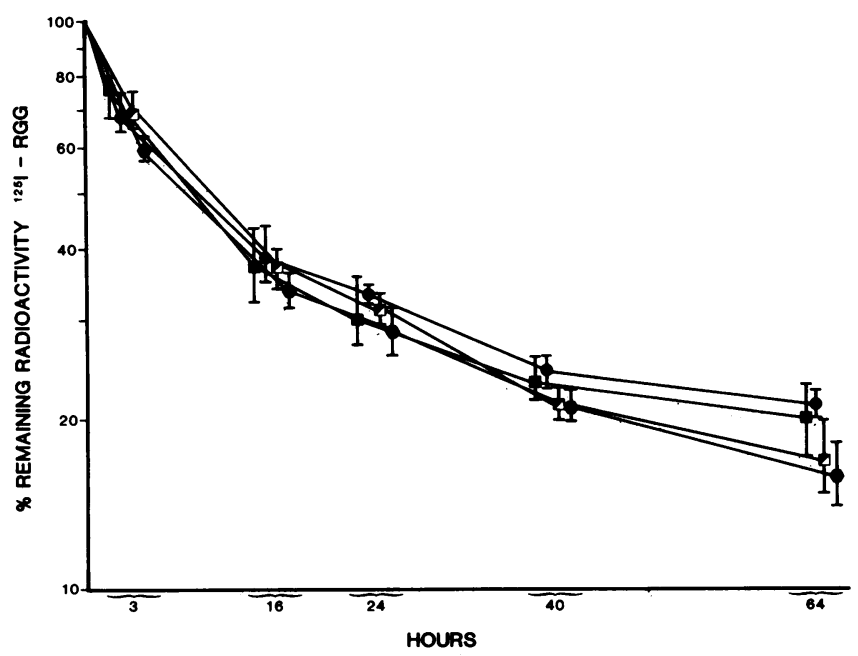

Figure 5. Plasma disappearance of ${ }^{125} \mathrm{I}-\mathrm{RGG}$ in male and female, normal or amyloid Syrian hamsters (๑, normal females $(\times 4)$; $\bullet$, normal males $(\times 4)$; $₫$, amyloid old females $(\times 3)$; $\bullet$, amyloid DES males $(\times 2)$ ). The presence of amyloid did not significantly affect the plasma metabolism of ${ }^{125} \mathrm{I}-\mathrm{RGG}$ or ${ }^{125} \mathrm{I}$-serum albumin (bovine and hamster, not shown). 
Table III. Organ Distribution of ${ }^{125}$ I-FP in Normal and Amyloidotic Hamsters 7 d After Intravenous Administration

\begin{tabular}{|c|c|c|c|c|c|c|c|}
\hline \multirow[b]{2}{*}{ Group } & \multirow{2}{*}{$\begin{array}{l}\text { Number } \\
\text { of } \\
\text { animals }\end{array}$} & \multirow{2}{*}{$\begin{array}{l}\text { Plasma } \\
\mathrm{cpm} \times 10^{3} / 0.1 \mathrm{ml}\end{array}$} & \multicolumn{5}{|c|}{${ }^{125} \mathrm{I}-\mathrm{FP} \mathrm{cpm}$ per gram of tissue/cpm per $0.1 \mathrm{ml}$ of plasma } \\
\hline & & & Liver* & Spleen & Kidney & Heart & Muscle \\
\hline & $n$ & & & & & & \\
\hline Normal females & 4 & $0.3 \ddagger(0.01-0.4)$ & $1.6(1-3)$ & $2.5(1-3)$ & $1.8(1-3)$ & $1 \quad(1)$ & $1.5(1-3)$ \\
\hline Normal males & 4 & $0.1 \quad(0.01-0.2)$ & $2.4(1-3)$ & $4 \quad(2-5)$ & $2.5(2-3)$ & $1.5(1-3)$ & $2.5(1-6)$ \\
\hline $\begin{array}{l}\text { Old female, } \\
\text { amyloid }\end{array}$ & 4 & $1.7(1-2.5)$ & $9 \quad(2-32) \S$ & $48 \quad(19-72) \S$ & $8.9(3.3-21) \S$ & $1.7(1.5-1.9)$ & $1.6(0.9-2.3$, \\
\hline $\begin{array}{l}\text { DES male, } \\
\text { amyloid }\end{array}$ & 3 & $1.7(0.5-3.6)$ & $31 \quad(12-65) \S$ & $13 \quad(4.1-29) \S$ & $14(3-24) \S$ & $2(1-3.4)$ & $1.6(0.7-2.8)$ \\
\hline $\begin{array}{l}\text { Turpentine, } \\
\text { female amyloid }\end{array}$ & 3 & $2.5 \quad(1.2-5.0)$ & $6.2(4.6-9) \S$ & $14.6(9.5-19) \S$ & $2.5(1.9-3.6) \S$ & $1.4(1.4)$ & $0.8(0.7-0.8)$ \\
\hline $\begin{array}{l}\text { Turpentine male, } \\
\text { no amyloid }\end{array}$ & 2 & $0.1 \quad(0.09-0.2)$ & $2.1(2-2.2)$ & $3.5(3-4)$ & $2.5(2-3)$ & $1.5(1-2)$ & $1.5(1-2)$ \\
\hline
\end{tabular}

* Livers perfused with phosphate-buffered saline before removal. $\ddagger$ Mean of group (range). $\S$ Organs with histologically proven amyloid.

spleen, kidney, heart, and muscle (rear leg flexor) and per 0.1 $\mathrm{ml}$ of plasma and the presence of amyloid was evaluated by Congo red birefringence. When compared to eight normal control hamsters, the seven amyloid hamsters (four old females, three DES males) had higher plasma levels of ${ }^{125} \mathrm{I}-\mathrm{FP}$ at necropsy (Table III) as expected from prolonged terminal plasma ${ }^{125}$ I-FP half-life (Fig. 3). The calculated organ/plasma ratios (Table III) indicated the amount of ${ }^{125} \mathrm{I}-\mathrm{FP}$ in amyloidcontaining organs (with liver and spleen greater than kidney) was much greater than in controls, where the absolute counts per minute were small. However, in amyloid hamsters, ${ }^{125} \mathrm{I}$ FP was sequestered only in amyloidotic organs, as nonamyloid tissue (heart and leg muscle) showed ${ }^{125}$ I-FP localization similar to controls. At the same time, five of the turpentine treated hamsters (Fig. 4) also were examined (Table III). All three amyloidotic females had high ${ }^{125}$ I-FP plasma levels with liver and spleen localization; minimal amyloid and ${ }^{125}$ I-FP localization were found in the kidney. An essentially normal organ distribution was found in the two turpentine males in which no amyloid was found.

In a similar fashion the tissue localization of ${ }^{125}$ I-RGG was determined in the amyloid and normal hamsters shown in Fig. 5, $8 \mathrm{~d}$ after ${ }^{125}$ I-RGG injection (Table IV). The serum levels of ${ }^{125} \mathrm{I}-\mathrm{RGG}$ were lower in the amyloid hamsters than in controls (in direct contrast to the ${ }^{125} \mathrm{I}-\mathrm{FP}$ results) and a similar distribution of ${ }^{125} \mathrm{I}-\mathrm{RGG}$ was found in all tissues from amyloidotic and normal hamsters. Therefore, the deposition of plasma ${ }^{125} \mathrm{I}-\mathrm{FP}$ in amyloid organs was specific for FP and not a general phenomenon.

Localization of ${ }^{125}$ I-FP in amyloid. Although intravenously injected ${ }^{125}$ I-FP specifically accumulated only in amyloidotic organs, it was necessary to determine whether the ${ }^{125} \mathrm{I}$-FP was actually in the amyloid areas of those organs. Accordingly, histologic sections were examined by autoradiography for coincidence of positive Congo red birefringence and radioactivity. High silver grain counts $\left({ }^{125} \mathrm{I}-\mathrm{FP}\right)$ were seen only over areas of amyloid. This is shown in Fig. 6, $A$ and $B$, which are paired photomicrographs of the same area of liver by transmitted light $(A)$, to see emulsion grains, and polarized light $(B)$, to see positive birefringent areas. These findings were consistently seen and easiest to appreciate in liver sections because of the discrete localization of amyloid in that organ. Amyloid per se did not induce appearance of silver grains as emulsions on control nonradioactive amyloid sections or ${ }^{125} \mathrm{I}$ RGG injected amyloidotic tissue sections were negative (not shown). Although all radioactivity was restricted to amyloid deposits, the density of grains was not directly related to density of amyloid as measured by intensity of birefringence or staining. Indeed, some areas of amyloid seemed to have a paucity of ${ }^{125} \mathrm{I}-\mathrm{FP}$. Fig. $6, C$ and $D$, shows an example of this finding in which two discrete areas of amyloid (arrows) were detected by polarized light (Fig. $6 \mathrm{D}$ ), although only the upper area was associated with high grain count (Fig. $6 C$ ). This observation suggested the existence of a subpopulation of

Table IV. Organ Distribution of ${ }^{125}$ I-RGG in Normal and Amyloidotic Hamsters 8 d After Intravenous Injection

\begin{tabular}{|c|c|c|c|c|c|c|c|}
\hline \multirow[b]{2}{*}{ Group } & \multirow{2}{*}{$\begin{array}{l}\text { Number } \\
\text { of } \\
\text { animals }\end{array}$} & \multirow{2}{*}{$\begin{array}{l}\text { Plasma } \\
\mathrm{cpm} \times 10^{3} / 0.1 \mathrm{ml}\end{array}$} & \multicolumn{3}{|c|}{${ }^{125} \mathrm{I}-\mathrm{FP} \mathrm{cpm}$ per gram of tissue $/ \mathrm{cpm}$ per $0.1 \mathrm{ml}$ of plasma } & \multirow[b]{2}{*}{ Heart } & \multirow[b]{2}{*}{ Muscle } \\
\hline & & & Liver* & Spleen & Kidney & & \\
\hline & $n$ & & & & & & \\
\hline $\begin{array}{c}\text { \&, ठ̊ normal } \\
\text { hamsters }\end{array}$ & 4 & $27.5(20-34) \ddagger$ & $0.23(0.14-0.26)$ & $1.3(1.1-1.5)$ & $1.1(1-1.3)$ & $0.8(0.6-1.1)$ & $0.4(0.3-0.5)$ \\
\hline $\begin{array}{l}\text { ९, ठ amyloid } \\
\text { hamsters }\end{array}$ & 5 & $12.8(12-16)$ & $0.7 \quad(0.4-1.1) \S$ & $2.2(1.5-3.3) \S$ & $1.2(0.8-1.8) \S$ & $1.0(0.6-1.2)$ & $0.76(0.3-1.0)$ \\
\hline
\end{tabular}

* Livers perfused with phosphate-buffered saline before removal. $\ddagger$ Mean of group (range). § Organs with histologically proven amyloid. 

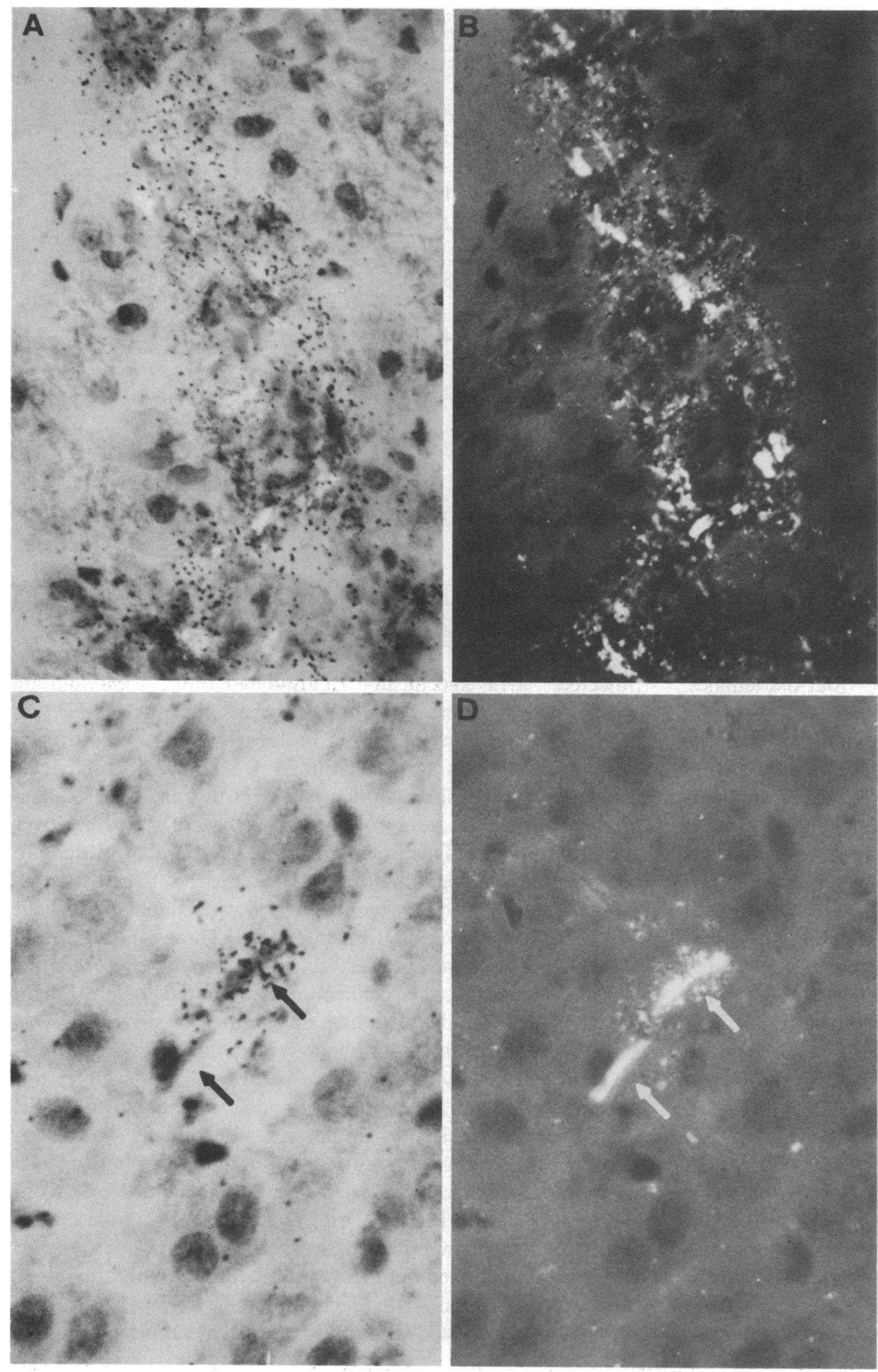

Figure 6. Photomicrographs of liver sections from amyloidotic hamsters injected intravenously $7 \mathrm{~d}$ earlier with ${ }^{125} \mathrm{I}$-FP (Fig. 3, Table III) after development of emulsion and staining by Congo red. $(A)$ Grains in developed emulsion from presence of ${ }^{125}$ IFP as seen by transmitted light microscopy. ( $B$ ) Same area (as in $A$ ) when seen by polarized light microscopy. Positive Congo red birefringent areas (white) correspond to area of radioactivity from ${ }^{125} \mathrm{I}$-FP. (C) Transmitted light; and $(D)$ polarized light-same area with two apparent deposits of amyloid (arrows). However, grains ( ${ }^{125}$ I-FP) are located primarily over upper deposit. The amyloid deposits in $C$ and $D$ were atypical but do exemplify the finding that occasional amyloid was not associated with ${ }^{125}$ I-FP, although high grain count ( ${ }^{125}$ I-FP) was seen only over amyloid deposits. $A, B, \times 150 ; C, D, \times 400$. amyloid which either differs by capacity or kinetics to bind FP.

\section{Discussion}

Amyloidosis was a common finding in the aging Syrian hamster and sex of the hamster was an important factor. Thus, amyloid was a consistent finding in females over 1 yr of age, whereas only half the 2-yr-old males were involved. Also, the amount of amyloid was greater in females inasmuch as male involvement frequently was minimal unless experimentally induced. These results are consistent with reports on other
Syrian hamster colonies $(20,23-29)$. The remarkable proclivity for amyloid deposition in hamster females may explain the observation that female hamsters die earlier than males (23, 24, 28-30). This reversal of the usual female longevity found in other mammals (30) has been attributed to extensive adrenal amyloidosis usually found in old female Syrian hamsters (24, $27,31)$.

In the present study, a sex difference also was found during experimental induction of amyloid with sterile $\mathrm{Na}$ caseinate or turpentine; longer treatments were required for males and resulted in less incidence and smaller deposits of amyloid. On the other hand, extensive amyloid was found in both males 
and females after DES treatment similar to other reports (20, $27,31,32$ ). Whereas amyloid formation after certain treatments ( $\mathrm{Na}$ caseinate) is common in different species, the deposition of amyloid after DES treatment to our knowledge is found only in the Syrian hamster. Of particular interest is the fact that treatment of males with DES also results in markedly increased serum FP levels (14). Injecting males with another estrogen (estradiol) also has resulted in increased serum FP levels and detectable amyloid (unpublished). Na caseinate injection of male hamsters results in moderately elevated FP levels (unpublished), which is not surprising considering that serum levels of FP increase as an acute phase protein in males (15). Therefore, predisposition for amyloid formation appears to correlate with high serum levels of FP present normally (as in female) or artificially induced (as in DES male). However, at present, it is unknown whether this correlation is etiologic in the Syrian hamster. Because serum levels (synthesis) of this SAP homologue can be controlled by exogenous hormones, experimental manipulation of serum FP levels may provide insight into the problem of whether FP is an obligate requirement for amyloid persistence or if FP has a primary or secondary role in amyloid formation.

Of particular interest was the dynamic exchange in vivo between serum FP and amyloid deposits in the diseased hamster. In contrast, previous studies measuring plasma disappearance of ${ }^{125} \mathrm{I}$-AP in mice did not find any difference between normal and amyloid animals (21). However, in the amyloidotic hamster, the plasma disappearance of ${ }^{125} \mathrm{I}-\mathrm{FP}$ was characteristically abnormal and actually was diagnostic for moderate deposits of amyloid. This altered plasma metabolism was seen with a number of ${ }^{125} \mathrm{I}$-FP preparations, and in various types of amyloid (i.e., normal old age, Na caseinate, DES, turpentine-induced) found in both sexes. The explanation for this phenomenon is moot. The rapid disappearance from intravascular compartment and subsequently slower plasma half-life may reflect damage to a FP-degrading system (such as liver) or a saturated catabolic system. However, the possibility exists that FP in the amyloidotic animal may be altered and that the injected normal ${ }^{125}$ I-FP may be selectively bound by amyloid.

It is clear that injected ${ }^{125}$ I-FP enters the amyloidotic tissue and is retained there in an extravascular pool for a prolonged time. Presumably the FP is not metabolized there, but may be altered while in contact with amyloid. Autoradiography of involved organs indicated that ${ }^{125} \mathrm{I}$-FP was concentrated only in amyloid deposits and not in normal tissue. However, $7 \mathrm{~d}$ after injection, the ${ }^{125}$ I-FP was not distributed uniformly in all the amyloid, which suggests a heterogeneity among amyloid deposits. Thus, some amyloid may not have FP-binding capacity, although preliminary results have not indicated any areas in hamster amyloid deposits which are devoid of FP. On the other hand, these nonradioactive areas could represent amyloid not in contact with tissue ${ }^{125} \mathrm{I}-\mathrm{FP}$, or high turnover deposits, which had already exchanged their ${ }^{125} \mathrm{I}-\mathrm{FP}$.

However, the binding of injected ${ }^{125} \mathrm{I}-\mathrm{FP}$ in amyloid in vivo was a specific process which was not seen with ${ }^{125}$ I-RGG and ${ }^{125} \mathrm{I}$-albumins. In a similar fashion, ${ }^{125} \mathrm{I}-\mathrm{FP}$ but not ${ }^{125} \mathrm{I}-$ RGG, will bind in vitro to isolated fibril preparations in a calcium-dependent fashion (unpublished), as previously shown with human SAP (33).

Actually the involvement of FP in hamster amyloid should not be surprising as the amino acid sequence at the amino- terminus showed such homology with human SAP (13). An especially elegant expression of this homology was found recently at the DNA level (Dowton et al., personal communication); that is, the hamster FP gene was identified by binding to a complementary DNA probe specific for human SAP. From the subsequently derived complete FP amino acid sequence, an overall closer homology with SAP (69\%) than with CRP (50\%) was apparent. However, as previously mentioned, FP can express certain CRP-like functions, such as complement activation after phosphorylcholine interaction, and these biologic activities may be etiologic in the inflammatory response associated with deposits of CRP (34-36). Inclusion of such a potential inflammatory agent in amyloid would seem inappropriate as amyloid characteristically elicits little inflammation, which may explain its usual longevity. However, hamster amyloid appears to be a typical noninflammatory deposit without evidence of complement activation by the FP component. Actually, FP may interact with amyloid in a unique fashion unknown for SAP; the dynamic extravascular transfer of injected ${ }^{125} \mathrm{I}-\mathrm{FP}$ and its subsequent sequestration in amyloid are certainly novel.

The abundance of this protein in female hamster is particularly intriguing, especially if these high levels somehow are instrumental in producing the prominent amyloid deposits and the early demise which is characteristic of this gender. If FP is indeed so damaging to females, one might speculate that it certainly must perform an essential function in the younger female and for this purpose the gene was preserved during Syrian hamster evolution.

\section{Acknowledgments}

The authors are grateful to Mr. Joe Lucero for technical help and to Dr. W. J. Hadlow and Dr. T. A. Waldmann for helpful discussions.

\section{References}

1. Rokitansky, C. 1842. In Handbuch der Pathologischen Anatomie. Braumuller u. Seidel, Wien. Vol. 3. 629.

2. Virchow, R. 1858. In Die Cellularpathologie in Ihrer Begrundung auf Physiologische und Pathologische Gewebelehre. A. Hirschwald, Berlin. 440.

3. Glenner, G. G. 1980. Amyloid deposits and amyloidosis-the B-fibrilloses. N. Engl. J. Med. 302:1283-1292; 1333-1343.

4. Pinteric, L., and R. H. Painter. 1979. Electron microscopy of serum amyloid protein in the presence of calcium: alternative forms of assembly of pentagonal molecules in two dimensional lattices. Can. J. Biochem. 57:727-736.

5. Painter, R. H., I. DeEscallon, A. Massey, L. Pinteric, and S. B. Stern. 1982. The structure and binding characteristics of serum amyloid protein. Ann. NY Acad. Sci. 389:199-215.

6. Osmand, A. P., B. Friedenson, H. Gewurz, R. H. Painter, T. Hofmann, and E. Shelton. 1977. Characterization of C-reactive protein and the complement subcomponent $\mathrm{C} 1 \mathrm{t}$ as homologous proteins displaying cyclic pentameric symmetry (pentraxins). Proc. Natl. Acad. Sci. USA. 74:739-743.

7. Levo, Y., B. Frangione, and E. C. Franklin. 1977. Amino acid sequence similarities between amyloid $P$ component, $C 1$ and CRP. Nature (Lond.). 268:56-57.

8. Pepys, M. B., A. C. Dash, T. C. Fletcher, N. Richardson, E. A. Munn, and A. Feinstein. 1978. Analogues in other mammals and in fish of human plasma proteins, $C$-reactive protein and amyloid $P$ component. Nature (Lond.). 273:168-170.

9. Baltz, M. L., F. C. deBeer, A. Feinstein, E. A. Munn, C. P. 
Milstein, T. C. Fletcher, J. F. March, J. Taylor, C. Bruton, J. R. Clamp, A. J. S. Davies, and M. B. Pepys. 1982. Phylogenetic aspects of C-reactive protein and related proteins. Ann. NY Acad. Sci. 389: 49-75.

10. Liu, T.-Y., F. A. Robey, and C.-M. Wang. 1982. Structural studies on C-reactive protein. Ann. NY Acad Sci. 389:151-162.

11. Robey, F. A., T. Tanaka, and T.-Y. Liu. 1983. Isolation and characterization of two major serum proteins from the dogfish, Mustelus canis, C-reactive protein and amyloid P component. J. Biol. Chem. 258:3889-3893.

12. Coe, J. E. 1977. A sex-limited serum protein of Syrian hamsters: definition of female protein and regulation by testosterone. Proc. Natl. Acad. Sci. USA. 74:730-733.

13. Coe, J. E., S. S. Margossian, H. S. Slayter, and J. A. Sogn. 1981. Hamster female protein. A new pentraxin structurally and functionally similar to $\mathrm{C}$-reactive protein and amyloid $\mathrm{P}$ component. J. Exp. Med. 153:977-991.

14. Coe, J. E. 1983. Homologs of CRP: a diverse family of proteins with similar structure. Contemp. Top. Mol. Immunol. 9:211-238.

15. Coe, J. E., and M. J. Ross. 1983. Hamster female protein. A divergent acute phase protein in male and female Syrian hamsters. J. Exp. Med. 157:1421-1433.

16. Cathcart, E. S., I. R. Comerford, and A. S. Cohen. 1965. Immunologic studies on a protein extracted from human secondary amyloid. N. Engl. J. Med. 273:143-146.

17. Bladen, H. A., M. V. Nylen, and G. G. Glenney. 1966. The ultrastructure of human amyloid as revealed by the negative staining technique. J. Ultrastruct. Res. 14:449-459.

18. Coe, J. E., and K. K. Takemoto. 1972. Immune response in the hamster. VI. Antibody response in polyoma oncogenesis. J. Natl. Cancer Inst. 49:39-44.

19. Puchtler, H., F. Sweat, and M. Levine. 1962. On the binding of Congo red by amyloid. J. Histochem. Cytochem. 10:355-364.

20. Dontenwill, W., H. Ranz, and U. Mohr. 1960. Experimentelle untersuchungen zur amyloidenlstehung beim goldhamster. Beitr. Pathol. Anat. 122:390-405.

21. Skinner, M., J. D. Sipe, R. A. Yood, T. Shirahama, and A. S. Cohen. 1982. Characterization of $P$ component (AP) isolated from amyloidotic tissue: Half-life studies of human and murine AP. Ann. NY Acad. Sci. 389:190-198.

22. Waldmann, T. A., and W. Strober. 1969. Metabolism of immunoglobulins. Prog. Allergy. 13:1-110.

23. Birt, D. F., and P. M. Pour. 1983. Influence of dietary fat on spontaneous lesions of Syrian golden hamsters. J. Natl. Cancer Inst. 71:401-406.
24. Schmidt, R. E., R. L. Eason, G. B. Hubbard, J. T. Young, and D. L. Eisenbrandt. 1983. Pathology of Aging Syrian Hamsters. CRC Press, Inc., Boca Raton, Florida. 219-242.

25. Dunham, L. J., and K. M. Herrold. 1962. Failure to produce tumors in the hamster check pouch by exposure to ingredients of betel guid: histopathologic changes in the pouch and other organs by exposure to known carcinogens. J. Natl. Cancer Inst. 29:1047-1067.

26. Gleiser, C. A., G. L. Van Hoosier, W. G. Sheldon, and W. K. Read. 1971. Amyloidosis and renal paramyloid in a closed hamster colony. Lab. Anim. Sci. 21:197-202.

27. Handler, A. H., and F. C. Chesterman. 1968. Spontaneous diseases. In The Golden Hamster, Its Biology and Use in Medical Research. R. A. Hoffman, P. F. Robinson, and H. Magalhaes, editors. Iowa State University Press, Ames, Iowa. 209-213.

28. McMartin, D. N. 1979. Morphologic lesions in aging Syrian hamsters. J. Gerontol. 34:502-511.

29. Dontenwill, W., H.-J. Chevalier, H.-P. Harke, U. Lafrenz, G. Reckzeh, and B. Schneider. 1974. Die generalisierte amyloidose des Syrischen Goldhamsters bei chronishen Berauchungsversuchen. $Z$. Versuchstierkd. 16:75-84.

30. Kirkman, H., and P. K. S. Yau. 1972. Longevity of male and female, intact and gonadectomized, untreated and hormone-treated, neoplastic and non-neoplastic Syrian hamsters. Am. J. Anat. 135:205220.

31. Franks, L. M., and F. C. Chesterman. 1957. Adrenal degeneration and tumor formation in the golden hamster following treatment with stilboestrol and methylcholanthrene. Br. J. Cancer. 11:105-111.

32. Russfield, A. B., and M. N. Green. 1965. Serum protein patterns associated with amyloidosis in the Syrian hamster. Am. J. Pathol. 46:59-67.

33. Pepys, M. B., R. F. Dyck, F. C. deBeer, M. Skinner, and A. S. Cohen. 1979. Binding of serum amyloid P-component (SAP) by amyloid fibrils. Clin. Exp. Immunol. 38:284-293.

34. Kushner, I., and M. H. Kaplan. 1961. Studies on acute phase protein. I. An immunohistochemical method for the localization of Creactive protein in rabbits: association with necrosis in local inflammatory lesions. J. Exp. Med. 114:961-975.

35. Parish, W. E. 1977. Features of human spontaneous vasculitis reproduced experimentally in animals. Effects of antiglobulins, Creactive protein and fibrin. Bayer-Symp. 6:117-151.

36. du Clos, T. W., C. Mold, P. Y. Paterson, J. Alroy, and H. Gewurz. 1981. Localization of C-reactive protein in inflammatory lesions of experimental allergic encephalomyelitis. Clin. Exp. Immunol. 43:565-573. 